\title{
BMJ Open Association between CVDs and initiation and adherence to statin treatment in patients with newly diagnosed hypercholesterolaemia: a retrospective cohort study
}

In Sun Ryou, ${ }^{1}$ Jooyoung Chang, ${ }^{2}$ Joung Sik Son, ${ }^{3}$ Ahryoung Ko, ${ }^{3}$ Seulggie Choi, ${ }^{2}$ Kyuwoong Kim, ${ }^{4}$ Sung Min Kim, ${ }^{2}$ Sang Min Park (i) ${ }^{5}$

To cite: Ryou IS, Chang J, Son JS, et al. Association between CVDs and initiation and adherence to statin treatment in patients with newly diagnosed hypercholesterolaemia: a retrospective cohort study. BMJ Open

2021;11:e045375. doi:10.1136/ bmjopen-2020-045375

- Prepublication history and additional supplemental materials for this paper is available online. To view these files, please visit the journal online (http://dx.doi.org/10. 1136/bmjopen-2020-045375).

ISR and JC contributed equally.

ISR and JC are joint first authors.

Received 02 0ctober 2020 Revised 15 March 2021 Accepted 23 March 2021

Check for updates

(c) Author(s) (or their employer(s)) 2021. Re-use permitted under CC BY-NC. No commercial re-use. See rights and permissions. Published by BMJ.

For numbered affiliations see end of article.

Correspondence to

Dr Sang Min Park

smpark.snuh@gmail.com

\section{ABSTRACT}

Objectives To evaluate the association between incident cardiovascular disease (CVD) and initiation and adherence to statin treatment for primary prevention of CVD in patients with newly diagnosed hypercholesterolaemia. Design A population-based retrospective cohort study. Setting This study used National Health Insurance Service-Health Screening Cohort (NHIS-HEALS) from Republic of Korea.

Participants This study included 11320 participants without previous history of CVD aged between 40 and 79 years who had elevated total cholesterol level (more than $240 \mathrm{mg} / \mathrm{dL}$ ) and had initiated statin treatment within 24 months of the national health screening from 2004 to 2012 identified in the NHIS-HEALS.

Primary and secondary outcome measures The primary outcome, CVD, was defined as first-ever admission or death due to ischaemic heart disease, acute myocardial infarction, revascularisation or stroke, or December 31 2013. The HRs of CVD according to statin adherence were calculated according to stratification by Systematic COronary Risk Evaluation.

Results Early statin initiation significantly lowered risk of CVD outcomes compared with late initiation (HR of late statin user, $1.24 ; 95 \% \mathrm{Cl} 1.02$ to 2.51 ). Among early initiators, statin discontinuers had a significantly higher risk for CVD compared with persistent users (HR, 1.71; $95 \% \mathrm{Cl} 1.10$ to 2.67), while statin reinitiators had an attenuated risk increase (HR 1.34, 95\% $\mathrm{Cl} 0.79$ to 2.30). Conclusions Among statin users with newly diagnosed hypercholesterolaemia, early statin initiation is associated with lower CVD risk compared with late initiation.

Furthermore, statin discontinuation is associated with increased risk of CVD, but reinitiation attenuated the risk.

\section{INTRODUCTION}

Statin use is known to reduce cardiovascular disease (CVD) morbidity and mortality according to numerous clinical trials in the primary prevention of CVD. ${ }^{1}$ While it is common practice to recommend statins for the primary prevention of $\mathrm{CVD},{ }^{2}{ }^{3}$ limited

\section{Strengths and limitations of this study}

- Since National Health Insurance Service provide health screenings biannually in Korea, this study is based on a nationally representative sample to evaluate statin adherence effect on cardiovascular disease.

- This study can minimise errors in patient selfreporting and non-response because the records were derived from health claims data the healthcare providers.

- Unlike conventional methods of assessing average drug compliance, such as medication possession ratio and proportion of days covered, this study evaluated statin adherence which more correctly represents focused on patient's drug-use habits according to following adherence classifications; early statin user (subdivided into persistent statin user, statin discontineur and reinitiator) and late statin user.

- This study could have an information bias because of nature of claims data.

- Because this study includes only Koreans who were subject to national health screening programme, generalisability might be limited in other populations residing elsewhere in the world.

evidence is available on whether prompt and early initiation of statins is beneficial. Besides, relatively low statin adherence and high discontinuation rate has been still shown in worldwide. ${ }^{4-6}$

According to WHO, only $50 \%$ of patients with chronic disease in developed countries adhere to their prescribed medications. ${ }^{7}$ Statin discontinuation rates was reported ranging from $10 \%$ to $44.7 \%$ at $6-12$ months. ${ }^{5-10}$ In addition, discontinuation rates are significantly higher in primary prevention patients than in secondary prevention patients. ${ }^{6911}$ 
It is well established that non-adherence to statin increases CVD morbidity and mortality. ${ }^{41-13}$ One prospective cohort study showed that statin discontinuation is associated with an increased risk of myocardial infarction (MI) and CVD death, ${ }^{14}$ and another a population-based cohort study has reported statin discontinuation any time during therapy was associated with a $67 \%$ risk increase for acute $\mathrm{MI}^{15}$ ensuring previous reports of the negative CVD effect of statin discontinuation. One study found adherence to statin therapy was associated with reduced CVD burden, while discontinuation correlated with increased CVD burden. ${ }^{16}$

While statin discontinuation poses considerable risk on CVD, relatively fewer studies addressed the issue of statin reinitiation and its benefits. Several studies have shown that a relatively large proportion of statin users discontinued their medication, but more than $50 \%$ of the statin discontinuers have re-initiated statins within a year. ${ }^{6} 1718$ However, these studies revealed statin discontinuation and reinitiation rates and their associated factors, and did not show whether statin reinitiation provided significant CVD benefit.

Therefore, we conducted a retrospective cohort study to investigate the CVD risk among statin users according to their adherence who initially began statin therapy for primary prevention of CVD.

\section{METHOD}

\section{Data acquisition}

We used the National Health Insurance Service-National Health Screening Cohort (NHIS-HEALS) ${ }^{19}$ provided by the National Health Insurance Service, ${ }^{20}$ South Korea. The Korean NHIS provides universal healthcare insurance for Korean nationals, and insured citizens of 40 years or older are eligible for a biennial health screening. The NHIS-HEALS, comprising of 514866 participants, is a cohort consisting of a $10 \%$ simple random sample of patients 40-79 years who received a health screening during years 2002 and 2003. The cohort data includes health screening laboratory results as well as socioeconomic status, claims for prescription medication, diagnosis codes, type of hospital visit, length of stay, date of death and cause of death.

\section{Cohort construction}

To ensure that patients of our study included only those who were newly diagnosed with high cholesterol through national health screening programme, we only considered patients who had a total cholesterol level of less than $240 \mathrm{mg} / \mathrm{dL}$ in their first health screening. Patient whose subsequent medical examinations were conducted between 1 January 2004 and 31 December 2012, and with a total cholesterol level of $240 \mathrm{mg} / \mathrm{dL}$ or higher and had no previous records of statin use or diagnosis of CVD or dyslipidaemia were considered for eligible study population.

For 6 months, newly diagnosed high-cholesterol patients were observed for initiation of statin medication (statin initiation period). If a patient received statin medication within 6 months of the health screening, the date of first prescription was considered the enrolment date. If a patient did not receive any medication until the end of the 6-month statin initiation period, he or she was enrolled on the last day. All patients were subsequently observed for statin adherence behaviours during the following 18 months (statin adherence period) and classified by their statin use. At the end of the statin adherence period (index date), patients were observed for the primary outcome of CVD and followed from the index date until the date of event, death or 31 December 2013, whichever came first (follow-up period) (figure 1).

\begin{tabular}{|c|c|c|c|}
\hline Statin initiation period & \multicolumn{2}{|c|}{ Statin adherence period } & Follow-up period \\
\hline 6 months & 6 months & 12 months & $\sim$ Dec. 31st, 2013 \\
\hline \multirow[t]{2}{*}{ No Statin Dispensed } & \multicolumn{2}{|l|}{ Statin non user } & \\
\hline & \multicolumn{2}{|l|}{ Late statin user } & \\
\hline \multirow{3}{*}{$\begin{array}{l}\text { Statin Dispensed } \\
=\text { Early statin user } \\
\text { first 6months period of statin } \\
\text { dispensed after health screening }\end{array}$} & \multicolumn{2}{|l|}{ Persistent statin user } & \\
\hline & \multicolumn{2}{|c|}{ Statin Discontineur } & \\
\hline & & Statin Reinitiator & \\
\hline$\uparrow$ & \multicolumn{2}{|l|}{$\uparrow$} & \\
\hline Date of Health Screening & \multicolumn{2}{|l|}{ Date of Study enrolment } & \\
\hline
\end{tabular}

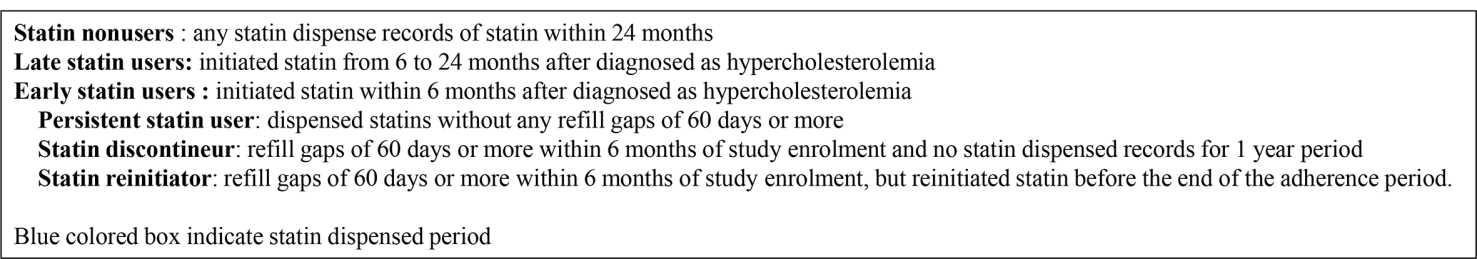

Figure 1 Operational definition of statin adherence. Only newly diagnosed hyperlipidaemia patients were targeted, and statin adherence was defined by drug dispensed records within 6 months after health screening, and subsequent 6 months and 12 months periods. 


\section{Patient adherence classification}

Early statin initiators initiated statins within 6 months of hypercholesterolaemia diagnosis, and late statin initiators initiated from 6 to 24 months after diagnosed as hypercholesterolaemia. During the 18-month statin adherence period, early statin initiators were categorised into persistent, discontinued and reinitiated users. First, those who did not have refill gaps greater than 60 days for 18 months were considered persistent users. Second, those who discontinued statin medication in the first 6 months and did not receive any statin until the end of the adherence period were considered discontinuers. Third, those who had a refill gap greater than 60 days in the first 6 months but received subsequent statin medication at least once until the end of the adherence period were considered re-initiators.

\section{Ascertainment of event outcomes}

CVD was defined as a two-time outpatient visits or onetime admission, or death based on the International Classification of Diseases 10th revision code of I20 I23, I24.8, I24.9, I60 I64, G45. Patients who received coronary procedures were additionally considered to have ischaemic heart disease (IHD). Secondary outcomes of stroke and IHD was determined.

\section{Ascertainment of covariates}

Covariates were determined during a 3-year lookback from the start of the follow-up period. Age was determined at the index date. Body mass index was categorised into $<23, \geq 23.0 \&<25.0, \geq 25 \mathrm{~kg} / \mathrm{m}^{2}$. Smoking status and drinking frequency were determined by the latest health screening survey. The most recent insurance premium rank was used as a surrogate marker to compute quartiles socioeconomic status. A systolic blood pressure of $140 \mathrm{~mm} \mathrm{Hg}$ or more or a diastolic blood pressure of $90 \mathrm{~mm} \mathrm{Hg}$ or more categorised as hypertensive patients. Charlson Comorbidity Score was determined using the diagnosis claims data. Those with fasting blood glucose of $126 \mathrm{mg} / \mathrm{dL}$ or more, or prescribed glucose lowering drugs with diabetes diagnosis was considered diabetic. Diagnosis of atrial fibrillation was determined by diagnosis of claims data. Concurrent aspirin and non-aspirin non-steroidal anti-inflammatory drugs (NSAIDs) were calculated using WHO Anatomic Therapeutic Chemical Classification Daily Defined Dose (DDD) ${ }^{21}$ unit and subsequently categorised into $<30$ DDDs, 30-180 DDDs or 180 DDDs or more. The number of outpatient visits was used to adjust for patterns of hospital use. European Society of Cardiology Systematic COronary Risk Evaluation (ESC SCORE) ${ }^{22}$ was calculated using the above data. Because Korea belongs to the low IHD mortality group according to the WHO Mortality database, ${ }^{23}$ we applied low risk SCORE chart to the subjects before enrolment for CVD risk stratification.

\section{Statistical analysis}

We computed HRs between statin user classifications using a Cox proportional hazards model adjusting for age, sex, body mass index, blood pressure, smoking habit, alcohol drinking frequency, exercise frequency, socioeconomic status, number of outpatient visits, Charlson Comorbidity Index, diabetes, atrial fibrillation, aspirin use and NSAID use. A Cox regression analysis was conducted with stratification by the ESC SCORE. Statistical analyses were performed using SAS V.9.4 (SAS Institute). A p $<0.05$ was considered to indicate statistical significance.

\section{Patient and public involvement}

Patients were not involved in developing the research questions, measuring outcome and designing the study.

\section{RESULTS}

Participants included a total of 51757 newly detected high-cholesterol patients, comprising of 11320 statin users, 40437 statin non-users. Among statin users, 6529 of early statin users categorised into statin persistent users, discontinuers and reinitiators. 1010 patients used statin persistently, 2800 patients discontinued statin and 861 patients reinitiated statin (figure 2). The baseline characteristics of statin users are shown in table 1 .

We compared with early statin initiators and late statin initiators which in total consisted of 445 events over 45494 person-years (figure 3). Late statin initiators had higher HRs of CVD referent to early statin initiators (HR 1.24; 95\% CI 1.02 to 1.51 ). According to a stratified analysis based on SCORE, among patients with SCORE greater or equal to 3, HRs of late statin initiators significantly more higher risk of CVD referent to early statin initiators (HR 1.71; 95\% CI 1.23 to 2.37). However, among patients who had SCORE less than 3, HRs of early initiators and late initiators were all attenuated and did not result in significantly.

We analysed the CVD risk of early statin initiators depending on the adherence after initiation (figure 4). Comparing subgroups of persistent statin users, discontinuers and reinitiators, our analysis consisted of a total of 152 events over 18120 person-years. Discontinuers had a greater risk of CVD referent to persistent users (HR 1.71; 95\% CI 1.10 to 2.67). Reinitiators did not have a significantly higher risk of CVD referent to persistent users (HR $1.35 ; 95 \%$ CI 0.79 to 2.30 ). Among patients with SCORE greater or equal to 3 , HRs of discontinuers remained significantly high referent to persistent users (HR 3.10; 95\% CI 1.25 to 7.67 ) and reinitiators did not experience a significantly higher risk of CVD (HR 1.48; 95\% CI 0.46 to 4.79). However, among patients who had SCORE less than 3 , HRs of discontinuers, and reinitiators were all attenuated and did not result in significantly higher risk referent to persistent users.

For secondary outcomes, late initiation significantly increased the risk of IHD over early statins initiation, but only marginally increased the risk of stroke (online supplemental table 1). The risks of discontinuation on IHD and stroke were similar to the main result but were 


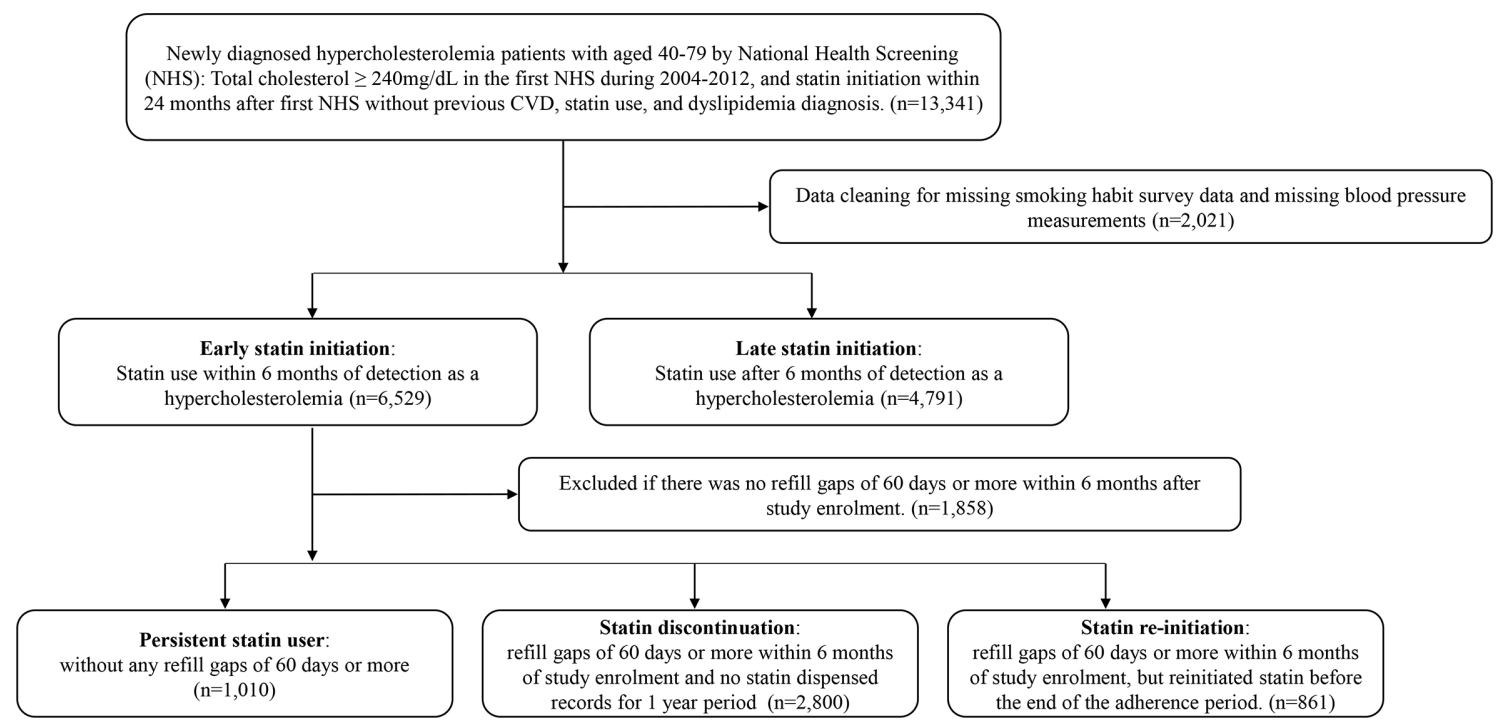

Figure 2 Flow of patient selection. This is the flow chart of study selection according to operational definition of statin adherence in our retrospective cohort study. CVD, cardiovascular disease.

attenuated due to a smaller number of respective cases (online supplemental table 2).

\section{DISCUSSION}

In this nationally representative retrospective cohort study, the findings of our study showed that early initiation of statin after being newly diagnosed with hypercholesterolaemia was associated with reduced risk of CVD compared with late initiation of statin. We also found that statin discontinuation was associated with an increased risk of CVD compared with persistent statin users, but the increased risk of CVD was attenuated by the reinitiation of statins.

In regard to reducing long-term risk of CVD in statin users, our study showed that early initiation of statin was beneficial compared with late initiators. It is well known that high low-density lipoprotein cholesterol (LDL-C) levels have a negative effect on CVD. ${ }^{324}$ We believe that not only the high LDL-C level itself, but also the long duration of exposure to high LDL-C is considered as a risk of CVD. ${ }^{25}$ The extended duration of exposure to high cholesterol levels because of late statin initiation may increase the risk of CVD, as shown in our results. This agrees with a previous genetic study which showed that the risk of CVD was related to the duration of LDL-C exposure. ${ }^{26}$ Since we could not verify the LDL-C level, we performed stratification analysis using a cardiovascular risk prediction tool, SCORE and found that the benefits of early onset were more pronounced in patients with moderate to severe SCORE risk, which might correspond to high LDL-C level. Furthermore, elevated circulating LDL-C is directly related to the progression of atherosclerosis. ${ }^{27}$ Statins improve antiatherosclerotic functions through lipid-lowering action and pleiotropic effects, ${ }^{28-31}$ so early initiation of statin improve endothelial function and reduce inflammation. ${ }^{27} 32$ We suggest that the early initiation of statins among newly diagnosed hypercholesterolaemia patients may have prevented structural atherosclerotic changes of their vasculature, which may have led to CVDs than the late statin initiators.

In addition, although previous studies also showed that statin administration shortly after the onset of an acute coronary syndrome was associated with a short-term reduction in mortality and acute myocardial infarction(AMI) recurrence rates, ${ }^{27}{ }^{33-35}$ these were focused on secondary prevention and limited to short-term outcomes. Our study addresses both issues and provides further evidence for long-term benefits of early initiation of statins for primary prevention. To the best of our knowledge, this is the first study to address the relationship between early initiation and the risk of CVD in the primary care setting.

Among early initiators of statin, statin discontinuation was associated with a $71 \%$ increase in the risk of CVD compared with persistent statin users in our study results. Non-adherence and discontinuation among statin users have been reported to have detrimental CVD outcomes compared with persistent users, ${ }^{4151636-39}$ and our results agree with previous studies. Despite the abundant evidence of the harmful effects caused by statin discontinuation, the analyses of health claims records derived from clinical practice show that statin compliance is poor in primary prevention. ${ }^{6} 91140$ Patients taking statins in primary prevention perceive that their vascular risk as low, ${ }^{8}$ and that the risk of statin-related side effects outweigh the vascular benefits, even though they rarely experience significant elevations in creatine kinase or other objective changes in realty. ${ }^{41-46}$ Furthermore, widespread media coverage of the risk of statin-related side effects was related to statin discontinuation among patients with high CVD risk. ${ }^{14} 47$ The risk-focused information provision of the media and the patient's misattribution of potential harmful sequelae can lead to the 
Table 1 Baseline characteristics of study population

\begin{tabular}{|c|c|c|c|c|c|}
\hline & \multirow{2}{*}{$\begin{array}{l}\text { Early } \\
\text { statin } \\
\text { initiator }\end{array}$} & \multirow{2}{*}{$\begin{array}{l}\text { Late } \\
\text { statin } \\
\text { initiator }\end{array}$} & \multicolumn{3}{|c|}{$\begin{array}{l}\text { Early statin initiators, by drug } \\
\text { adherence }\end{array}$} \\
\hline & & & Persistent & Reinitiator & Discontinuer \\
\hline $\begin{array}{l}\text { No of patients, } \\
n\end{array}$ & 6529 & 4791 & 1010 & 861 & 2800 \\
\hline
\end{tabular}

Age, years, \%

\begin{tabular}{|c|c|c|c|c|c|}
\hline $40-49$ & 13.5 & 16.4 & 8.9 & 13.5 & 16.4 \\
\hline $50-59$ & 53.5 & 52.2 & 51.7 & 57.1 & 52.5 \\
\hline $60-69$ & 24.3 & 23.2 & 26.6 & 22.3 & 23.2 \\
\hline$\geq 70$ & 8.7 & 8.2 & 12.8 & 7.1 & 7.9 \\
\hline \multicolumn{6}{|l|}{ Sex, \% } \\
\hline Male & 35.8 & 37.4 & 36.3 & 32.5 & 38.4 \\
\hline \multicolumn{6}{|c|}{ Body mass index, $\mathrm{kg} / \mathrm{m}^{2}, \%$} \\
\hline$<23$ & 33 & 29.2 & 27.7 & 31 & 35.5 \\
\hline $\begin{array}{l}\geq 23.0 \text { and } \\
<25.0\end{array}$ & 29.7 & 30 & 28.3 & 30 & 30.3 \\
\hline$\geq 25$ & 37.2 & 40.8 & 44 & 39 & 34.3 \\
\hline \multicolumn{6}{|c|}{ Smoking status, \% } \\
\hline Never & 76.8 & 77.2 & 77.1 & 78.3 & 74.9 \\
\hline Past & 10.6 & 9.2 & 10.4 & 9.5 & 10.9 \\
\hline Current & 12.6 & 13.6 & 12.5 & 12.2 & 14.2 \\
\hline \multicolumn{6}{|c|}{ Drinking frequency, per week, \% } \\
\hline None & 73.1 & 74 & 71.1 & 75.5 & 72.1 \\
\hline $1-2$ & 16.8 & 15.6 & 18 & 14.9 & 17.3 \\
\hline$\geq 3$ & 9.9 & 10.1 & 10.7 & 9.4 & 10.4 \\
\hline \multicolumn{6}{|c|}{ Exercise frequency, per week, \% } \\
\hline None & 28.4 & 34.9 & 24.8 & 29.6 & 29.6 \\
\hline $1-2$ & 36.8 & 33.2 & 38.9 & 37.8 & 36.8 \\
\hline$\geq 3$ & 34.9 & 31.9 & 36.3 & 32.6 & 33.7 \\
\hline \multicolumn{6}{|c|}{ Socioeconomic status, $\%$} \\
\hline Q1 & 22.8 & 23.7 & 20.3 & 26.1 & 22.8 \\
\hline Q2 & 25 & 24.7 & 24.6 & 26.6 & 24.9 \\
\hline Q3 & 34.9 & 34.2 & 35.2 & 32.1 & 35.5 \\
\hline Q4 & 17.3 & 17.4 & 20 & 15.2 & 16.8 \\
\hline
\end{tabular}

Blood pressure (BP), Systolic BP/Diastolic BP $\mathrm{mm} \mathrm{Hg}$ \%

\begin{tabular}{|c|c|c|c|c|c|}
\hline 140 and $<90$ & 74 & 69.7 & 61.1 & 76.7 & 78 \\
\hline$\geq 140$ or $\geq 90$ & 26 & 30.3 & 38.9 & 23.3 & 22 \\
\hline \multicolumn{6}{|c|}{ Charlson Comorbidity Index, \% } \\
\hline 0 & 28.2 & 26.8 & 31 & 27.5 & 29.1 \\
\hline $1-2$ & 60.1 & 59.2 & 57.7 & 58.9 & 61.3 \\
\hline$\geq 3$ & 11.7 & 14 & 11.3 & 13.6 & 9.6 \\
\hline \multicolumn{6}{|l|}{ SCORE, \% } \\
\hline$<1 \%$ & 25.3 & 26.9 & 17 & 28.5 & 27.7 \\
\hline $1 \%$ & 35.6 & 35 & 34.9 & 36 & 34.3 \\
\hline $2 \%$ & 19.8 & 20 & 24.6 & 18.7 & 19 \\
\hline $3 \%-4 \%$ & 13.2 & 12.7 & 15.8 & 11.9 & 13.1 \\
\hline$\geq 5 \%$ & 6 & 5.4 & 7.7 & 5 & 5.9 \\
\hline \multicolumn{6}{|l|}{ Diabetes, \% } \\
\hline Yes & 9.7 & 12.2 & 17 & 7.6 & 7.5 \\
\hline \multicolumn{6}{|c|}{ Atrial fibrillation, \% } \\
\hline Yes & 0.5 & 0 & 1.2 & 0.6 & 0.6 \\
\hline
\end{tabular}

Continued
Table 1 Continued

\begin{tabular}{|c|c|c|c|c|c|}
\hline & \multirow{2}{*}{$\begin{array}{l}\text { Early } \\
\text { statin } \\
\text { initiator }\end{array}$} & \multirow{2}{*}{$\begin{array}{l}\text { Late } \\
\text { statin } \\
\text { initiator }\end{array}$} & \multicolumn{3}{|c|}{$\begin{array}{l}\text { Early statin initiators, by drug } \\
\text { adherence }\end{array}$} \\
\hline & & & Persistent & Reinitiator & Discontinuer \\
\hline Aspirin & 16.9 & 21.1 & 33.6 & 16.1 & 8.6 \\
\hline NSAID & 41.8 & 41.6 & 44.9 & 43.4 & 36.7 \\
\hline
\end{tabular}

NSAID, non-steroidal anti-inflammatory drug; SCORE, Systematic COronary Risk Evaluation.

nocebo effect, which can lead to statin discontinuation, especially in primary prevention. ${ }^{48-50}$ Since discontinuation and underutilisation of statins may be due to the lack of awareness of the risk of dyslipidaemia, ${ }^{49}$ or the nocebo effect, ${ }^{50}$ it is needed to do efforts to educate about the benefits of persistent statin use and the detriment effect of discontinuation. In addition, we believe that those who have discontinued need motivation and clinical recommendation to reinitiate statins, but there is a lack of evidence showing the benefits of statin re-initiation among those who initially discontinued statins.

Our results showed that statin reinitiation among those who initially stopped their medication attenuated the risk of CVD compared with those who discontinued altogether, and statin reinitiators did not have a significantly higher risk of CVD referent to persistent users. Statin reinitiation among those who initially discontinued statin is a common phenomenon in clinical practice, ${ }^{61718}$ but previous studies have focused only on the aspects of statin utilisation and average drug compliance. They did not show the impact of statin reinitiation on CVD risk. A study of familial hypercholesterolaemia patients showed that statin discontinuation deteriorated the flow-mediated vasodilatation within 36 hours, which was recovered by reinitiation. ${ }^{30}$ This paper suggests that statin discontinuation can cause sudden endothelial dysfunction, ${ }^{28}{ }^{29}$ which can be recovered by statin reinitiation, but does not show its effects on the long-term risk of CVD. We assessed the risk of CVD among statin reinitiators and provided evidence that reinitiation attenuates the risk caused by discontinuation. We believe such evidence will help patients and clinicians to make informed judgements in reinitiating statins among patients who have initially discontinued their statin medication.

\section{Limitations}

There are several limitations to consider when interpreting our results. First, our study may have misclassification bias because we used data collected for administrative purposes of insurance claims and reimbursement. There was an inaccuracy in information such as diagnosis code or procedure code, which might have caused misclassification of study population. ${ }^{51}{ }^{52}$ However, previous validation studies have shown that the diagnostic codes of the NHI claims data in Korea was about seventy percent accurate and fairly reliable ${ }^{53}$ In addition, we used a strict operational definition of CVD and excluded patients with previous history of CVD, hypercholesterolaemia or statin 
Main

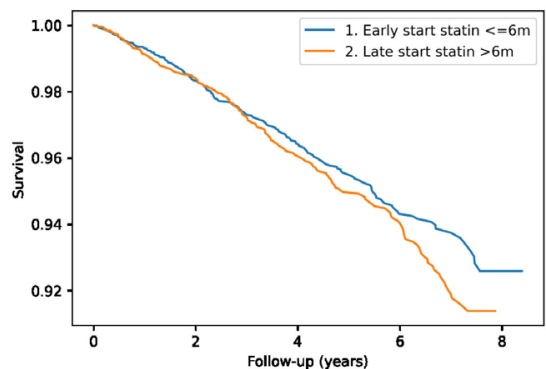

Early Initiators† Late initiators*

$\begin{array}{rcc}\text { Person-years } & 25,264 & 20,230 \\ \text { Cases } & 231 & 214 \\ \text { **aHR }(95 \% \mathrm{CI}) & 1 \text { (ref.) } & \mathbf{1 . 2 4}(\mathbf{1 . 0 2 - 1 . 5 1 )} \\ \text { P-value } & & 0.0291\end{array}$

Stratified by $\mathrm{SCORE}<3$

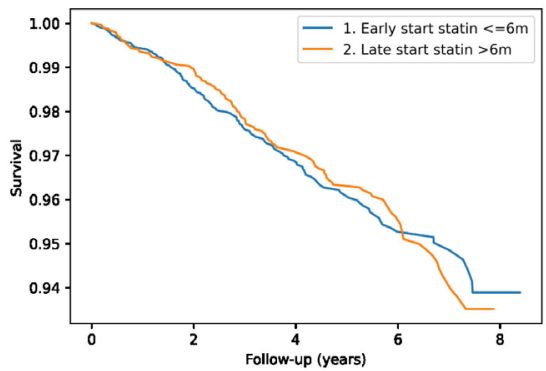

Early Initiators $\dagger$ Late initiators $\$$

\begin{tabular}{rc|c} 
Person-years & 20,135 & 16,638 \\
Cases & 156 & 129 \\
\hline$*$ aHR $(95 \% \mathrm{Cl})$ & $1(\mathrm{ref})$ & $1.04(0.81-1.33)$ \\
P-value & & 0.7415
\end{tabular}

Stratified by SCORE $\geq 3$

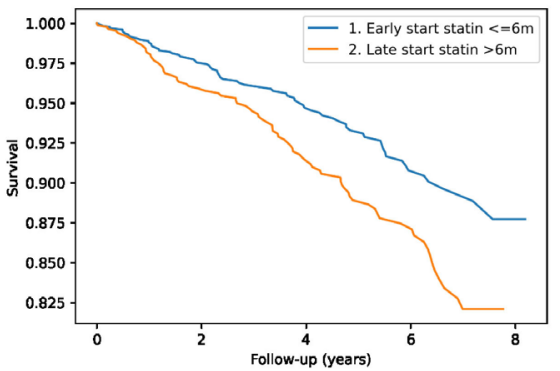

Early Initiators $\dagger \quad$ Late initiators

\begin{tabular}{|r|c|c|} 
Person-years & 5,129 & 3,592 \\
\hline Cases & 75 & 85 \\
\hline$*$ aHR $(95 \% \mathrm{CI})$ & $1($ ref. $)$ & $\mathbf{1 . 7 1 ( 1 . 2 3 - 2 . 3 7 )}$ \\
P-value & & 0.0013
\end{tabular}

Figure 3 Estimated HR of cardiovascular disease based on early or late statin initiation. †Initiated statin within 6 months of diagnosis. ‡initiated statin 24 months of diagnosis. ${ }^{* *}$ Adjusted for age, sex, body mass index, blood pressure, smoking habit, alcohol drinking frequency, exercise frequency, socioeconomic status, Charlson Comorbidity Index, diabetes, number of outpatient visits, atrial fibrillation, aspirin use and NSAID. HRs significant at $p<0.050$ are shown in bold. aHR, adjusted HR; NSAID, non-steroidal anti-inflammatory drug; SCORE, Systematic COronary Risk Evaluation.

medication from our aseline sample to minimise misclassification biases. Second, our study is sampled from only those who have undergone health check-ups which may lead to a selection bias. However, given that $98 \%$ of Koreans are enrolled in the National Health Insurance $^{53}$ and receive regular national health check-ups, the selection and recruitment bias of our cohort is likely minimal. ${ }^{54}$ Third, our study includes only Koreans, and the results may not be generalisable to other ethnicities. Studies suggest varying degrees of and varying reasons for non-adherence of statin among different countries and ethnicities. ${ }^{556}$ Therefore, the risk association of CVD and reinitiation may not be the same for other populations. Lastly, we used serum total cholesterol for the definition of hypercholesterolaemia. This definition can include those with high high-density lipoproten cholesterol (HDL-C) and normal LDL-C levels, or otherwise healthy individuals, which may have affected the results. However, our analysis of persistent, discontinued and re-initiated users and comparison between early initiation and late initiation groups were all those who had started statin medication based on the physician's judgement for need of statin. Therefore, in retrospect, the high total cholesterol patients are likely to be high LDL-C patients. Nevertheless, we conducted a sensitivity analysis of individuals stratified by SCORE. The adverse effects of statin discontinuation and the somewhat preventive effect of statin reinitiation have been shown to be more remarkable in
Main

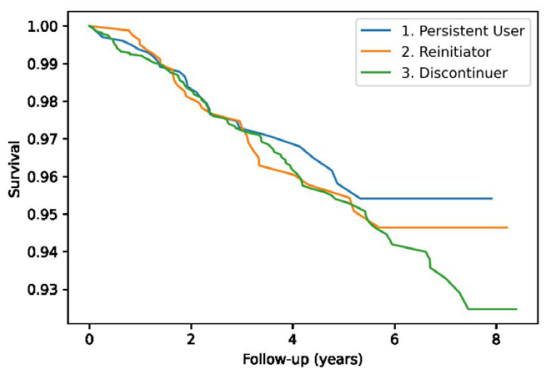

Persistent User Re-initiator Discontinuer

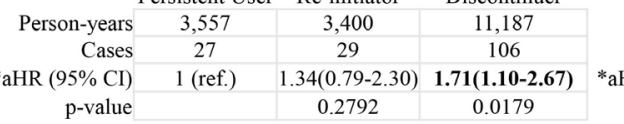

Stratified by SCORE $<3$
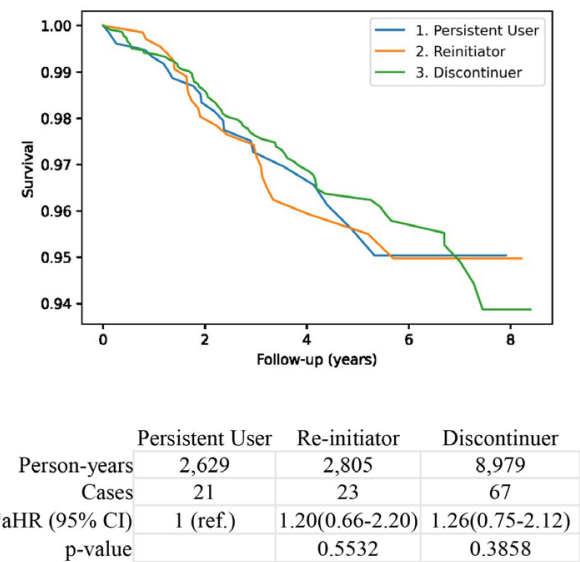
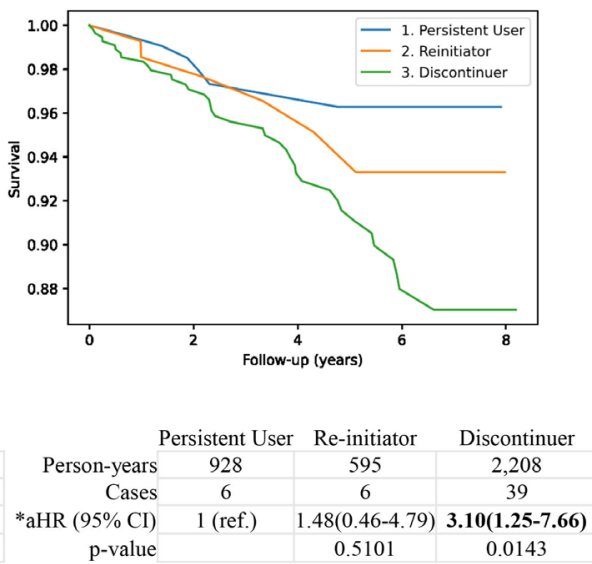

Figure 4 Estimated HR for cardiovascular disease based on adherence to statin treatment. *Adjusted for age, sex, body mass index, blood pressure, smoking habit, alcohol drinking frequency, exercise frequency, socioeconomic status, Charlson Comorbidity Index, diabetes, number of outpatient visits, atrial fibrillation, aspirin use and NSAID. HRs significant at $p<0.050$ are shown in bold. aHR, adjusted HR, NSAID, non-steroidal anti-inflammatory drug. 
the above moderate cardiovascular risk group (SCORE $\geq 3$ ). This demonstrates the reasoning for using statin for primary prevention in patients with moderate to severe cardiovascular risk. ${ }^{2357}$

\section{Future directions}

From our study results, it is important to provide information to patients who need statin for primary prevention of CVD to use statin early and persistently and reinitiate if they discontinued. While the CVD risk attenuation of reinitiation is apparent in our study, our work does not investigate causes for discontinuation, the dosing and type of statin when patients reinitiate, nor patients who discontinue more than once. Further work addressing these issues is warranted to determine how patients should reinitiate statin treatment.

\section{CONCLUSION}

Early statin initiation among patients with newly diagnosed hypercholesterolaemia lowers the risk of CVD compared with late statin initiation. Among early initiators, statin discontinuation was associated with an increased CVD risk, but statin reinitiation attenuated the risk increase in CVD.

\section{Author affiliations}

${ }^{1}$ Family Medicine, Ewha Womans University School of Medicine, Seoul, Korea (the Republic of)

${ }^{2}$ Department of Biomedical Sciences, Seoul National University College of Medicine, Seoul, Korea (the Republic of)

${ }^{3}$ Family Medicine, Seoul National University Hospital, Jongno-gu, Korea (the Republic of)

${ }^{4}$ Division of Cancer Control and Policy; National Cancer Survivorship Center, National Cancer Control Institute, National Cancer Center, Gyeonggi-do, Korea (the Republic of)

${ }^{5}$ Department of Family Medicine, Seoul National University Hospital, Jongno-gu, Korea (the Republic of)

Contributors SMP had full access to all of the data in the study and takes responsibility for the integrity of the data and the accuracy of the data analysis. Study concept and design: ISR, JC, SMP. Acquisition of data: JC. Analysis and interpretation of data: ISR, JC, SMP, JSS, AK, SC, KK SMK. Drafting of the manuscript: IR, JC, SMP. Critical revision of the manuscript: ISR, JC, SMP, JSS, AK, SC, KK and SMK. Statistical analysis: JC. Administrative, technical or material support: ISR.

Funding This research was supported by the the Basic Science Research Program through the National Research Foundation of Korea funded by the Ministry of Education (grant number 2017R1D1A1B03033721) and the Seoul National University Hospital research fund (grand number 04-2018-0370).

Competing interests None declared.

Patient consent for publication Not required.

Ethics approval The National Health Insurance Service-National Health Screening Cohort is strictly anonymised. And the need for patient consent was waived by the ethics committee of the Institutional Review Board at Seoul National University (IRB number: E-1509-004-699).

Provenance and peer review Not commissioned; externally peer reviewed.

Data availability statement Data may be obtained from a third party and are not publicly available. Data cannot be shared publicly because health information data which are collected, managed and maintained by the National Health Insurance Corporation to be modified as requested in the purpose of policy and academic research. The data are provided by Statistic analysis tool in 'Data analysis room' located within the National Health Insurance Corporation in which PC for review and analysis of data is installed.

Supplemental material This content has been supplied by the author(s). It has not been vetted by BMJ Publishing Group Limited (BMJ) and may not have been peer-reviewed. Any opinions or recommendations discussed are solely those of the author(s) and are not endorsed by BMJ. BMJ disclaims all liability and responsibility arising from any reliance placed on the content. Where the content includes any translated material, BMJ does not warrant the accuracy and reliability of the translations (including but not limited to local regulations, clinical guidelines, terminology, drug names and drug dosages), and is not responsible for any error and/or omissions arising from translation and adaptation or otherwise.

Open access This is an open access article distributed in accordance with the Creative Commons Attribution Non Commercial (CC BY-NC 4.0) license, which permits others to distribute, remix, adapt, build upon this work non-commercially, and license their derivative works on different terms, provided the original work is properly cited, appropriate credit is given, any changes made indicated, and the use is non-commercial. See: http://creativecommons.org/licenses/by-nc/4.0/.

ORCID iD

Sang Min Park http://orcid.org/0000-0002-7498-4829

\section{REFERENCES}

1 Collaboration CTT. Efficacy and safety of LDL-lowering therapy among men and women: meta-analysis of individual data from 174,000 participants in 27 randomised trials, 2015.

2 US Preventive Services Task Force, Bibbins-Domingo K, Grossman DC, et al. Statin use for the primary prevention of cardiovascular disease in adults: US preventive services Task force recommendation statement. JAMA 2016;316:1997-2007.

3 Arnett DK, Blumenthal RS, Albert MA, et al. 2019 ACC/AHA guideline on the primary prevention of cardiovascular disease: a report of the American College of Cardiology/American Heart Association Task Force on Clinical Practice Guidelines. J Am Coll Cardiol 2019;74:e177-232.

4 Rodriguez F, Maron DJ, Knowles JW, et al. Association of statin adherence with mortality in patients with atherosclerotic cardiovascular disease. JAMA Cardiol 2019;4:206-13.

5 Colantonio LD, Rosenson RS, Deng L, et al. Adherence to statin therapy among US adults between 2007 and 2014. J Am Heart Assoc 2019;8:e010376.

6 Booth JN, Colantonio LD, Chen L, et al. Statin discontinuation, reinitiation, and persistence patterns among Medicare beneficiaries after myocardial infarction: a cohort study. Circ Cardiovasc Qual Outcomes 2017;10:e003626.

7 Bosworth HB, Granger BB, Mendys P, et al. Medication adherence: a call for action. Am Heart J 2011;162:412-24.

8 Marrs JC, Kostoff MD. Discontinuation of statins: what are the risks? Curr Atheroscler Rep 2016;18:41.

9 Sigglekow F, Horsburgh S, Parkin L. Statin adherence is lower in primary than secondary prevention: a national follow-up study of new users. PLoS One 2020;15:e0242424.

10 Ofori-Asenso R, Ilomäki J, Tacey M, et al. Predictors of first-year nonadherence and discontinuation of statins among older adults: a retrospective cohort study. Br J Clin Pharmacol 2019;85:227-35.

11 Ellis JJ, Erickson SR, Stevenson JG, et al. Suboptimal statin adherence and discontinuation in primary and secondary prevention populations. J Gen Intern Med 2004;19:638-45.

12 Hirsh BJ, Smilowitz NR, Rosenson RS, et al. Utilization of and adherence to guideline-recommended lipid-lowering therapy after acute coronary syndrome: opportunities for improvement. J Am Coll Cardiol 2015;66:184-92.

13 Vupputuri S, Joski PJ, Kilpatrick R, et al. LDL cholesterol response and statin adherence among high-risk patients initiating treatment. Am J Manag Care 2016;22:e106-15.

14 Nielsen SF, Nordestgaard BG. Negative statin-related news stories decrease statin persistence and increase myocardial infarction and cardiovascular mortality: a nationwide prospective cohort study. Eur Heart J 2016;37:908-16.

15 De Vera MA, Choi H, Abrahamowicz M, et al. Statin discontinuation and risk of acute myocardial infarction in patients with rheumatoid arthritis: a population-based cohort study. Ann Rheum Dis 2011;70:annrheumdis 142455

16 De Vera MA, Choi H, Abrahamowicz M, et al. Impact of statin discontinuation on mortality in patients with rheumatoid arthritis: a population-based study. Arthritis Care Res 2012;64:809-16. 
17 Vinogradova Y, Coupland C, Brindle P, et al. Discontinuation and restarting in patients on statin treatment: prospective open cohort study using a primary care database. BMJ 2016;353:i3305

18 Caspard H, Chan AK, Walker AM. Compliance with a statin treatment in a usual-care setting: retrospective database analysis over 3 years after treatment initiation in health maintenance organization enrollees with dyslipidemia. Clin Ther 2005;27:1639-46.

19 Seong SC, Kim Y-Y, Park SK, et al. Cohort profile: the National health insurance Service-National health screening cohort (NHIS-HEALS) in Korea. BMJ Open 2017;7:e016640.

20 Cheol Seong S, Kim Y-Y, Khang Y-H, et al. Data resource profile: the National health information database of the National health insurance service in South Korea. Int J Epidemiol 2017;46:799-800.

21 ATC classification index with DDDs. WHO collaborating centre for drug statistics methodology, Oslo, (NOR), 2017.

22 Piepoli MF, Hoes AW, Agewall S, et al. 2016 European guidelines on cardiovascular disease prevention in clinical practice: The Sixth Joint Task Force of the European Society of Cardiology and Other Societies on Cardiovascular Disease Prevention in Clinical Practice (constituted by representatives of 10 societies and by invited experts) Developed with the special contribution of the European Association for Cardiovascular Prevention \& Rehabilitation (EACPR). Eur Heart $J$ 2016;37:2315-81.

23 Falk E, Mortensen MB. Statin therapy on the basis of hope: a European perspective. J Am Coll Cardiol 2016;68:2903-6.

24 Stone NJ, Robinson JG, Lichtenstein AH, et al. 2013 ACC/ AHA guideline on the treatment of blood cholesterol to reduce atherosclerotic cardiovascular risk in adults: a report of the American College of Cardiology/American heart association Task force on practice guidelines. J Am Coll Cardiol 2014;63:2889-934.

25 Akyea RK, Kai J, Qureshi N, et al. Sub-optimal cholesterol response to initiation of statins and future risk of cardiovascular disease. Heart 2019;105:975-81.

26 Ference BA, Yoo W, Alesh I, et al. Effect of long-term exposure to lower low-density lipoprotein cholesterol beginning early in life on the risk of coronary heart disease: a Mendelian randomization analysis. J Am Coll Cardiol 2012;60:2631-9.

27 Stenestrand U, Wallentin L, Swedish Register of Cardiac Intensive Care (RIKS-HIA). Early statin treatment following acute myocardial infarction and 1-year survival. JAMA 2001;285:430-6.

28 Alonso R, Mata P, De Andres R, et al. Sustained long-term improvement of arterial endothelial function in heterozygous familial hypercholesterolemia patients treated with simvastatin. Atherosclerosis 2001;157:423-9.

29 Lai W-T, Lee K-T, Chu C-S, et al. Influence of withdrawal of statin treatment on proinflammatory response and fibrinolytic activity in humans: an effect independent on cholesterol elevation. Int J Cardiol 2005:98:459-64.

30 Taneva E, Borucki K, Wiens L, et al. Early effects on endothelial function of atorvastatin $40 \mathrm{mg}$ twice daily and its withdrawal. $A m \mathrm{~J}$ Cardiol 2006;97:1002-6.

31 Cubeddu LX, Seamon MJ. Statin withdrawal: clinical implications and molecular mechanisms. Pharmacotherapy 2006:26:1288-96.

32 Tsiara S, Elisaf M, Mikhailidis DP. Early vascular benefits of statin therapy. Curr Med Res Opin 2003;19:540-56.

33 Okazaki S, Yokoyama T, Miyauchi K, et al. Early statin treatment in patients with acute coronary syndrome: demonstration of the beneficial effect on atherosclerotic lesions by serial volumetric intravascular ultrasound analysis during half a year after coronary event: the establish study. Circulation 2004;110:1061-8.

34 Nagashima M, Koyanagi R, Kasanuki $\mathrm{H}$, et al. Effect of early statin treatment at standard doses on long-term clinical outcomes in patients with acute myocardial infarction (the heart Institute of Japan, department of cardiology statin evaluation program). Am J Cardiol 2007;99:1523-8.

35 Kim MC, Ahn Y, Cho JY, et al. Benefit of early statin initiation within 48 hours after admission in statin-naïve patients with acute myocardial infarction undergoing percutaneous coronary intervention. Korean Circ J 2019;49:419.
36 Shalev V, Goldshtein I, Porath A, et al. Continuation of statin therapy and primary prevention of nonfatal cardiovascular events. Am J Cardiol 2012;110:1779-86.

37 Bouchard M-H, Dragomir A, Blais L, et al. Impact of adherence to statins on coronary artery disease in primary prevention. $\mathrm{Br} \mathrm{J}$ Clin Pharmacol 2007;63:698-708.

38 De Vera MA, Bhole V, Burns LC, et al. Impact of statin adherence on cardiovascular disease and mortality outcomes: a systematic review. Br J Clin Pharmacol 2014;78:684-98.

39 Giral P, Neumann A, Weill A, et al. Cardiovascular effect of discontinuing statins for primary prevention at the age of 75 years: a nationwide population-based cohort study in France. Eur Heart $J$ 2019;40:3516-25.

40 Vonbank A, Drexel H, Agewall S, et al. Reasons for disparity in statin adherence rates between clinical trials and real-world observations: a review. Eur Heart J Cardiovasc Pharmacother 2018;4:230-6.

41 Mann DM, Woodward M, Muntner P, et al. Predictors of nonadherence to statins: a systematic review and meta-analysis. Ann Pharmacother 2010;44:1410-21.

42 Brewer NT, Chapman GB, Brownlee S, et al. Cholesterol control, medication adherence and illness cognition. Br J Health Psychol 2002;7:433-47.

43 Stroes ES, Thompson PD, Corsini A, et al. Statin-associated muscle symptoms: impact on statin therapy-European atherosclerosis society consensus panel statement on assessment, aetiology and management. Eur Heart J 2015;36:1012-22.

44 Zhang H, Plutzky J, Skentzos S, et al. Discontinuation of statins in routine care settings: a cohort study. Ann Intern Med 2013;158:526-34.

45 Lakey WC, Greyshock NG, Kelley CE, et al. Statin intolerance in a referral lipid clinic. J Clin Lipidol 2016;10:870-9.

46 Bradley CK, Wang TY, Li S, et al. Patient-reported reasons for declining or discontinuing statin therapy: insights from the palm registry. J Am Heart Assoc 2019;8:e011765.

47 Matthews A, Herrett E, Gasparrini A, et al. Impact of statin related media coverage on use of statins: interrupted time series analysis with UK primary care data. BMJ 2016;353:i3283.

48 Nelson AJ, Puri R, Nissen SE. Statins in a distorted mirror of media. Curr Atheroscler Rep 2020;22:1-8.

49 Wadhera RK, Steen DL, Khan I, et al. A review of low-density lipoprotein cholesterol, treatment strategies, and its impact on cardiovascular disease morbidity and mortality. J Clin Lipidol 2016;10:472-89.

50 Tobert JA, Newman CB. The nocebo effect in the context of statin intolerance. J Clin Lipidol 2016;10:739-47.

51 Park B, Sung J, Park K. Strategies to improve the validity of diagnostic codes of national health insurance claims data. Seoul: Health Insurance Review and Assessment Services, 2002: 118-9.

$52 \mathrm{Kim} \mathrm{J}$. Strategies to enhance the use of national health insurance claims database in generating health statistics. Seoul: Health Insurance Review and Assessment Services, 2005.

$53 \mathrm{Kim}$ JA, Yoon S, Kim LY, et al. Towards actualizing the value potential of Korea health insurance review and assessment (HIRA) data as a resource for health research: strengths, limitations, applications, and strategies for optimal use of HIRA data. J Korean Med Sci 2017;32:718.

54 Lee J, Lee JS, Park S-H. Cohort profile: the national health insurance service-national sample cohort (NHIS-NSC), South Korea. Int J Epidemiol 2016;46:e15.

55 Albright KC, Zhao H, Blackburn J, et al. Racial differences in statin adherence following hospital discharge for ischemic stroke. Neurology 2017;88:1839-48.

56 Naito R, Miyauchi K, Daida H. Racial differences in the cholesterollowering effect of statin. J Atheroscler Thromb 2017;24:19-25.

57 Williams B, Mancia G, Spiering W, et al. 2018 ESC/ESH guidelines for the management of arterial hypertension. Eur Heart $J$ 2018:39:3021-104. 